\title{
ESTUDO DA RELAÇÃO PEDOMORFOGEOLÓGICA NA DISTRIBUIÇÃO DE SOLOS COM HORIZONTES B TEXTURAL E B NÍTICO NA PAISAGEM DE LAVRAS (MG) ${ }^{(1)}$
}

\author{
Marilusa Pinto Coelho Lacerda ${ }^{(2)}$, Jean Joel Gabriel Queménéur ${ }^{(3)}$, \\ Hélcio Andrade ${ }^{(4)}$, Helena Maria Ramos Alves ${ }^{(5)}$ \& Tatiana Grossi \\ Chquillof Vieira ${ }^{(6)}$
}

\begin{abstract}
RESUMO
O entendimento das relações entre geologia, geomorfologia e pedologia auxilia nas atividades de classificação dos solos e na avaliação da distribuição pedológica de uma área. Este trabalho foi motivado pela escassez de estudos dessa natureza na região de Lavras (MG), onde ocorrem várias classes de solos, relacionados com a grande variedade petrológica do material de origem e com a ocorrência de domínios geomorfológicos distintos. O objetivo deste trabalho foi estudar as relações entre material de origem (relação pedogeológica), classes de relevo (relação pedogeomorfológica) e solos com horizontes B textural e B nítico, visando propor um modelo da distribuição desses solos na paisagem de Lavras. Os solos com horizontes $B$ textural e $B$ nítico de ocorrência regional foram selecionados de acordo com o estádio de evolução, que permite preservar características das rochas parentais. Esses solos são desenvolvidos nessa região em relevos ondulados a forte ondulados, originando diferentes classes de solos com horizontes B textural e B nítico relacionados ao material de origem. Para desenvolvimento deste estudo, foram realizadas a interpretação petrológica do substrato rochoso e a individualização do relevo, por meio de classes de declividade. Mediante campanhas de campo, foram selecionados e caracterizados perfis representativos das principais classes dos solos em estudo e foram avaliadas as relações pedogeológicas associadas às relações pedogeomorfológicas, permitindo a
\end{abstract}

\footnotetext{
(1) Trabalho com financiamento da FAPEMIG. Recebido para publicação em outubro de 2005 e aprovado em setembro de 2007.

${ }^{(2)}$ Professora da Faculdade de Agronomia e Medicina Veterinária da Universidade de Brasília - FAV/UnB. Caixa postal 4508, CEP 70910-970 Brasília (DF). E-mail: marilusa @unb.br

${ }^{(3)}$ Professor do Departamento de Geologia do Instituto de Geociências da Universidade Federal de Minas Gerais - DG/IGC/ UFMG. Caixa Postal 2.608, CEP 31270-901 Belo Horizonte (MG). E-mail: jeanjoel@ig.ufmg.br

(4) Professor do Departamento de Ciência do Solo da Universidade Federal de Lavras - DCS/UFLA. Caixa Postal 37, CEP 37200.000 Lavras (MG). E-mail: handrade@ufla.br.

${ }^{(5)}$ Pesquisadora da Embrapa Café, Campus da UFLA. Caixa Postal 176, CEP 37200-000 Lavras (MG). E-mail: helena@ufla.br

${ }^{(6)}$ Pesquisadora da Empresa de Pesquisa Agropecuária de Minas Gerais, EPAMIG/CTSM E-mail: tatiana @ufla.br
} 


\begin{abstract}
proposição de um modelo preditivo de distribuição de solos com horizontes $B$ textural e B nítico na paisagem de Lavras (MG).
\end{abstract}

Termos de indexação: pedogênese, petrologia, classes de declividade, solos com B textural, solos com B nítico.

\title{
SUMMARY: STUDY OF THE RELATIONSHIP PEDO-GEOMORPHOLOGICAL IN THE SOIL DISTRIBUTION WITH ARGILLIC HORIZONS IN THE LANDSCAPE OF LAVRAS (MG), BRAZIL
}

\begin{abstract}
The understanding of the relationships between geology, geomorphology and pedology underlies activities of soil classification and the evaluation of the pedological distribution of an area. This study was motivated by the lack of reports of this nature for the region of Lavras (MG), where several soil classes occur, related to a great petrological variety in the parent material and different geomorphological domains. The objective was to study the relationships between parent materials (pedogeological relationship), relief classes (pedogeomorphological relationship) and soils with argillic horizons, to propose a distribution model of these soils in the said landscape. Soils with argillic horizons of regional occurrence were selected due to the evolution stage with preserved parent rock characteristics. Such soils are developed in this region on slopes between 12 and $45 \%$, generating different soil classes with argillic horizons related to the parent material. For this study, the rock substratum petrology was interpreted and the geomorphology individualized, by means of slopes classes. In field trips, representative profiles of the main soil classes were selected and characterized and the pedogeological and pedogeomorphological relationships were evaluated, underlying the proposal of a soil distribution model for the landscape of Lavras (MG).
\end{abstract}

Index terms: pedogenesis, petrology, slope classes, soils with argillic horizons, geomorphology, soils.

\section{INTRODUÇÃO}

Estudos de gênese e filiação de solos a partir de caracterização petrológica dos materiais de origem auxiliam nas atividades de classificação dos solos e na avaliação da distribuição pedológica de uma dada área, possibilitando, ainda, obter informações acerca dos atributos físicos, químicos e mineralógicos dos solos.

Na maioria dos casos, no entanto, observa-se que os estudos que envolvem relação entre atributos dos solos e materiais de origem são genéricos, abrangendo grandes grupos de rochas, sem individualização petrológica. Estudos geoquímicos do substrato rochoso permitem melhor compreensão dessa relação. Relações entre as classes de solo com unidades geomorfológicas, também, devem ser avaliadas, visto que o relevo apresenta papel crítico na pedogênese.

Estudos interdisciplinares, envolvendo geologia, geomorfologia e pedologia, podem ser empregados na avaliação e elaboração de modelos preditivos da distribuição das classes de solos na paisagem (Oliveira, 2005; Resende et al., 2005). Buol et al. (1989) relatam que os pedólogos pioneiros, como Fallou, Hilgard, Dokuchaiev, Glinka, Orth, Stremme, Marbut, Jenny, entre outros, destacavam, desde os primórdios, que a pedologia deveria ser uma ciência interdisciplinar.
Segundo Clemente (1988), as pesquisas que envolvem relações entre rochas e classes de solo evoluíram a partir da década de 1960, com o surgimento de estudos pedológicos específicos de perfis de alteração e gênese de solos. Dentre esses estudos destacam-se os trabalhos clássicos de Delvigne (1965) e Boulet (1978), entre tantos outros.

A partir desses trabalhos, foram realizados no Brasil estudos que apresentaram evolução do conhecimento dos mecanismos de formação dos produtos de alteração e pedogênese. No entanto, os trabalhos sobre o tema são raros, uma vez que no Brasil há grande diversidade litológica, mostrando os mais variados ambientes geológicos. Nessa linha de pesquisa, podem ser destacados os trabalhos de Cerri (1979), Oliveira (1980), Gonçalves (1987), Menegotto \& Gasparetto (1987), Clemente (1988), Gasparetto \& Menegotto (1995), entre outros.

Este trabalho foi motivado pela escassez de estudos dessa natureza na região de Lavras e inspirado nos estudos específicos sobre alteração e pedogenêse, que contribuem para o entendimento dos processos de gênese e distribuição dos solos em relação à variação geomorfológica e petrológica dos materiais de origem.

Na região de Lavras são comuns trabalhos que envolvem caracterização mineralógica, física e química 
e, por vezes, relação dos solos com a paisagem e material de origem genérico, destacando-se os de Andrade(1979), Curi et al. (1990), Silva et al. (1993) e Giarola (1994), entre outros. Dos trabalhos que correlacionam solos e material de origem, podem-se ressaltar os de Rocha (1982), Marques Jr. (1988) e Marques Jr. et al. (1992).

Assim, este trabalho objetivou o estudo das relações entre material de origem (relação pedogeológica), classes de relevo (relação pedogeomorfológica) e solos com horizontes B textural e B nítico, a fim de se propor um modelo preditivo da distribuição desses solos na paisagem da região de Lavras (MG).

\section{MATERIAL E MÉTODOS}

A área selecionada para o estudo compreende $972 \mathrm{~km}^{2}$ e está limitada pelas coordenadas UTM (Fuso 23): 7.660 a $7.642 \mathrm{~km}$ e 492 a $546 \mathrm{~km}$, compreendendo porções das cartas planialtimétricas do IBGE Lavras, Nepomuceno, Carmo da Cachoeira, Itumirim, Nazareno e Itutinga, todas em escala 1:50.000 (Figura 1).

Os dados referentes à geologia foram extraídos do mapa geológico inédito (Figura 2), em escala 1:50.000, proposto por Quéméneur (1995), com individualização

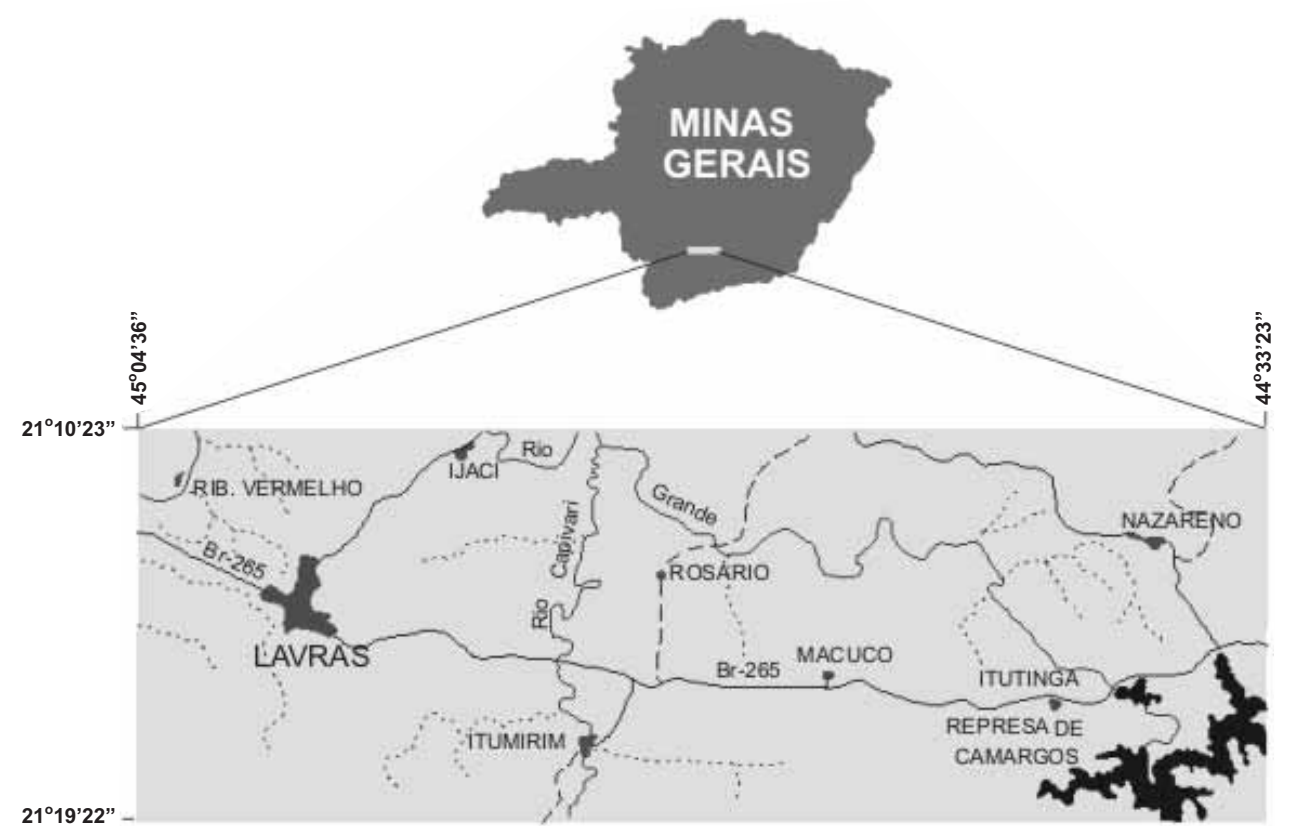

Figura 1. Mapa de localização da área estudada.

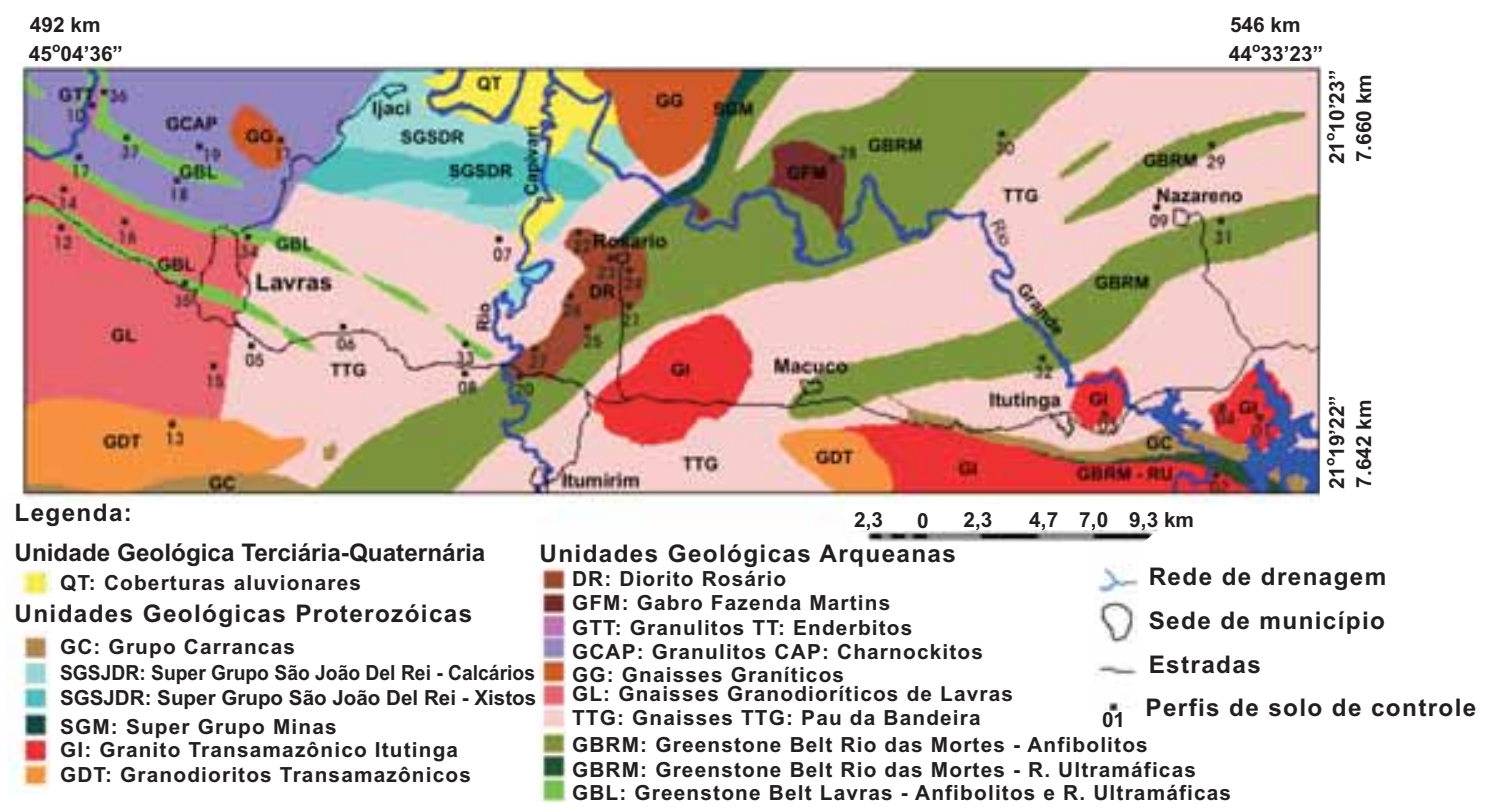

Figura 2. Mapa geológico da região de Lavras (MG) (Quéméneur, 1995), com locação dos perfis de controle estudados. 
petrológica e geocronológica das unidades geológicas, descritas no quadro 1. Esse mapeamento foi realizado com base em análises geoquímicas e geocronológicas das rochas, uma vez que estas são macroscopicamente muito semelhantes. As composições geoquímicas médias que permitiram a individualização das unidades geológicas ígneas Arqueanas e Proterozóicas utilizadas neste estudo encontram-se nos quadros 2 e 3 (Quéméneur, 1995).

Os solos com horizontes B textural e B nítico foram selecionados para estudo em razão do seu estádio de evolução, que permite a preservação de características herdadas dos materiais de origem.

\section{Relação pedogeomorfológica}

A avaliação das relações entre as classes de solos e classes de relevo, representado por classes de declividade, baseou-se no modelo pedogeomorfológico do município de Lavras (Quadro 4) estabelecido por Andrade et al. (1998). Foram realizadas campanhas de campo para checagem deste modelo, com enfoque sobre os solos com horizontes B textural e B nítico, uma vez que a área de estudo abrange vários outros municípios (Nepomuceno, Carmo da Cachoeira, Itumirim, Nazareno e Itutinga), além de Lavras.

Percorreu-se toda a área, investigando a relação entre as classes de solos com horizontes B textural e B nítico e as classes de declividade de ocorrência destes solos (12 a $24 \mathrm{~cm} \mathrm{~m}^{-1}$ ), utilizando o mapa de classes de declividade da área em estudo, obtido de Lacerda (1999), com individualização das classes de declive conforme modelo estabelecido por Andrade (1998). Nas campanhas de campo, as classes de declividade foram checadas por intermédio de leituras com clinômetro, estabelecendo-se a relação pedogeomorfológica da área de estudo.

\section{Relação pedogeológica}

Foram realizadas atividades de campo para estabelecimento das relações pedogeológicas, direcionadas a partir da localização geográfica e do reconhecimento das unidades petrológicas pertencentes às unidades geológicas ígneas Arqueanas e Proterozóicas. As observações foram concentradas em regiões com classes de relevo que correspondem à ocorrência de solos com horizontes B textural e B nítico na área de estudo, de acordo com a relação pedogeomorfológica estabelecida. As unidades petrológicas foram criteriosamente identificadas no campo, juntamente com a interpretação dos dados referentes às suas análises geoquímicas.

Foram avaliados 240 perfis de solos com horizontes B textural e B nítico, denominados perfis de reconhecimento, que foram georreferenciados por meio de GPS de navegação GARMIN ${ }^{\circledR}$. A identificação pedológica foi realizada por meio de caminhamento livre, de acordo com Embrapa (1989), com densidade de observações estabelecida em função do objetivo do trabalho e da extensão e homogeneidade da área de estudo.

\section{Quadro 1. Unidades geológicas de ocorrência na área de estudo}

\begin{tabular}{|c|c|}
\hline Unidade geológica & Composição petrológica \\
\hline \multicolumn{2}{|c|}{ Unidades geológicas ígneas Arqueanas } \\
\hline TTG: Gnaisse Pau da Bandeira & Trondhjemítica-tonalítica-granodiorítica \\
\hline GL: Gnaisse Granodiorítico de Lavras & Granodiorítica \\
\hline GG: Gnaisses Graníticos & Granítica \\
\hline GCAP: Granulitos Calcio-Alcalino Potássicos - Charnockitos & Calcio-Alcalina Potássica - Charnockítica \\
\hline GTT: Granulitos - Trondhjemítico-Tonalíticos - Enderbitos & Trondhjemítica-tonalítica - Enderbítica \\
\hline GBRM: Greenstone-belt Rio das Mortes - Anfibolitos & Anfibolítica (composição básica) \\
\hline GBRM: Greenstone-belt Rio das Mortes - Rochas Ultrabásicas & Piroxenítica (composição ultrabásica) \\
\hline GBL: Greenstone-belt de Lavras - Anfibolitos & Anfibolítica (composição básica) \\
\hline GBL: Greenstone-belt de Lavras - Rochas Ultrabásicas & Piroxenítica (composição ultrabásica) \\
\hline \multicolumn{2}{|c|}{ Unidades geológicas ígneas Arqueanas - Maciços Intrusivos } \\
\hline DR: Diorito do Rosário & Diorítica (composição sub-básica) \\
\hline GFM: Gabro da Fazenda Martins & Gabróica (composição básica) \\
\hline \multicolumn{2}{|c|}{ Unidades Geológicas Ígneas Proterozóicas (Transamazônicas) } \\
\hline GI: Granito Transamazônico de Itutinga & Granítica \\
\hline GDT: Granodiorito Transamazônico & Granodiorítica \\
\hline \multicolumn{2}{|c|}{ Unidades Geológicas Metassedimentares Proterozóicas } \\
\hline SGM: Supergrupo Minas & $\begin{array}{l}\text { Fácies Psamo-pelítica, Fácies Carbonatada, } \\
\text { Fácies Ferruginosa }\end{array}$ \\
\hline GC: Grupo Carrancas & Psamo-pelítica \\
\hline SGSJDR: Supergrupo São João Del Rei & Fácies Psamo-pelítica, Fácies Carbonatada \\
\hline
\end{tabular}

Fonte: Quéméneur (1995). 
Quadro 2. Composição geoquímica média (elementos maiores) das unidades geológicas ígneas Arqueanas

\begin{tabular}{|c|c|c|c|c|c|c|c|}
\hline \multirow{2}{*}{ Óxido } & \multicolumn{7}{|c|}{ Unidade geológica ígnea Arqueana } \\
\hline & TTG & GL & GG & GCAP & GTT & GBRM e $\mathrm{GBL}^{(1)}$ & GBRM e $\operatorname{GBL}^{(2)}$ \\
\hline $\mathrm{SiO}_{2}$ & 70,27 & 71,08 & 74,11 & 69,02 & 70,00 & 48,54 & 46,00 \\
\hline $\mathrm{Al}_{2} \mathrm{O}_{3}$ & 14,89 & 13,58 & 13,09 & 13,48 & 15,81 & 13,26 & 7,51 \\
\hline $\mathrm{Fe}_{2} \mathrm{O}_{3}$ & 2,43 & 3,63 & 2,35 & 4,40 & 2,31 & 3,25 & 12,87 \\
\hline $\mathrm{FeO}$ & - & - & - & - & - & 11,95 & - \\
\hline $\mathrm{MnO}$ & 0,064 & 0,04 & 0,049 & 0,065 & 0,036 & 0,25 & - \\
\hline $\mathrm{MgO}$ & 0,57 & 0,62 & 0,53 & 0,64 & 0,86 & 6,39 & 18,35 \\
\hline $\mathrm{CaO}$ & 1,94 & 1,75 & 1,34 & 2,38 & 2,81 & 10,16 & 6,71 \\
\hline $\mathrm{Na}_{2} \mathrm{O}$ & 4,77 & 4,04 & 3,68 & 3,64 & 5,71 & 2,09 & \\
\hline $\mathrm{K}_{2} \mathrm{O}$ & 2,75 & 3,96 & 4,12 & 4,20 & 1,45 & 0,41 & 0,45 \\
\hline $\mathrm{TiO}_{2}$ & 0,26 & 0,47 & 0,37 & 0,68 & 0,30 & 1,93 & 0,45 \\
\hline $\mathrm{P}_{2} \mathrm{O}_{5}$ & 0,09 & 0,14 & 0,11 & 0,19 & 0,10 & 0,24 & - \\
\hline $\mathrm{Cr}_{2} \mathrm{O}_{3}$ & - & - & - & - & - & 0,031 & - \\
\hline $\mathrm{NiO}$ & - & - & - & - & - & 0,029 & - \\
\hline
\end{tabular}

TTG: Gnaisses TTG - Gnaisse Pau da Bandeira; GL: Gnaisse Granodiorítico de Lavras; GG: Gnaisses Graníticos; GCAP: Granulitos Cálcio-Alcalino-Potássicos - Charnockitos; GTT: Granulitos Tonalítico-Trondhjemíticos - Enderbitos.

${ }^{(1)}$ GBRM e GBL: Anfibolitos - Greenstone-belt Rio das Mortes e Greenstone-belt de Lavras. ${ }^{(2)}$ GBRM e GBL: Rochas Ultrabásicas - Greenstone-belt Rio das Mortes e Greenstone-belt de Lavras.

Fonte: Quéméneur (1995).

Quadro 3. Composição geoquímica média (elementos maiores) das unidades geológicas ígneas Arqueanas e Proterozóicas

\begin{tabular}{|c|c|c|c|c|}
\hline \multirow[t]{2}{*}{ Óxido } & \multicolumn{2}{|c|}{$\begin{array}{c}\text { Unidade geológica ígnea } \\
\text { Arqueana - maciço intrusivo }\end{array}$} & \multicolumn{2}{|c|}{$\begin{array}{c}\text { Unidade geológica ígnea } \\
\text { Proterozóica }\end{array}$} \\
\hline & DR & GFM & GI & GDT \\
\hline & & 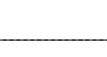 & & \\
\hline $\mathrm{SiO}_{2}$ & 64,19 & 54,16 & 73,66 & 68,00 \\
\hline $\mathrm{Al}_{2} \mathrm{O}_{3}$ & 15,92 & 16,02 & 13,48 & 15,26 \\
\hline $\mathrm{Fe}_{2} \mathrm{O}_{3}$ & 5,28 & 8,60 & 1,64 & 3,93 \\
\hline $\mathrm{FeO}$ & - & - & - & - \\
\hline $\mathrm{MnO}$ & 0,08 & 0,13 & 0,016 & 0,053 \\
\hline $\mathrm{MgO}$ & 2,25 & 5,86 & 0,19 & 1,11 \\
\hline $\mathrm{CaO}$ & 4,57 & 7,78 & 0,85 & 2,66 \\
\hline $\mathrm{Na}_{2} \mathrm{O}$ & 4,30 & 3,50 & 3,39 & 4,56 \\
\hline $\mathrm{K}_{2} \mathrm{O}$ & 1,40 & 0,97 & 5,61 & 2,93 \\
\hline $\mathrm{TiO}_{2}$ & 0,56 & 0,67 & 0,114 & 0,72 \\
\hline $\mathrm{P}_{2} \mathrm{O}_{5}$ & & 0,25 & 0,04 & 0,26 \\
\hline
\end{tabular}

DR: Diorito do Rosário; GFM: Gabro da Fazenda Martins; GI: Granito de Itutinga; GDT: Granodioritos Transamazônicos. Fonte: Quéméneur (1995).

\section{Perfis de solos de reconhecimento}

Os 240 perfis de reconhecimento avaliados encontram-se distribuídos por todas as unidades geológicas ígneas Arqueanas e Proterozóicas presentes na área - desenvolvidos em classes de declividade de
12 a $45 \mathrm{~cm} \mathrm{~m}^{-1}$ - que representam as classes de solo com horizontes B textural e B nítico de ocorrência regional, ou seja: Argissolo Vermelho-Amarelo (PVA), Argissolo Vermelho (PV) e Nitossolo Vermelho férrico (NVf) por vezes com associação de Chernossolo Argilúvico férrico (MTf). Nestes perfis foram 
Quadro 4. Modelo de relação pedogeomorfológica do município de Lavras (MG)

\begin{tabular}{lll}
\hline \multicolumn{1}{c}{ Classe de declividade } & Classe de relevo & Classe de solo \\
\hline $\mathrm{cm} \mathrm{m}^{-1}$ & & \\
$0-3$ (Topo) & Plano de topo & Latossolos \\
$0-3$ (Planície de inundação aluvial) & Plano de várzea & Solos Hidromórficos e Neossolos Flúvicos \\
$3-12$ & Suave ondulado & Latossolos \\
$12-24$ & Ondulado & Solos com B Textural \\
$24-45$ & Forte ondulado & Solos com B Textural e esporadicamente Cambissolos \\
$>45$ & Montanhoso & Cambissolos, Neossolos Litólicos e Afloramentos Rochosos
\end{tabular}

Fonte: Andrade et al. (1998).

realizadas classificações pedológicas expeditas, com avaliação de alguns atributos morfológicos de fácil identificação no campo (cor, textura, estrutura, cerosidade e atração magnética), além de observações dos solos no ambiente, especialmente com relação ao material de origem e relevo local e regional.

Entre os atributos avaliados, enfatizou-se a caracterização da cor e atração magnética, que se encontram diretamente relacionadas aos teores de óxidos de Fe dos solos (Oliveira et al., 1992; Embrapa, 1999), por ser a cor de Munsell considerada atributo morfológico de discriminação de algumas classes de solos com horizontes B textural e B nítico no segundo nível categórico do Sistema Brasileiro de Classificação de Solos - SiBCS (Embrapa, 1999), particularmente nos Argissolos e Nitossolos.

Esta etapa visou à classificação expedita das classes de solos, assim como o estabelecimento da relação pedogeológica preliminar da área de estudo.

\section{Perfis de solos de controle}

A avaliação pedológica expedita dos 240 perfis de reconhecimento permitiu selecionar 37 deles, denominados de controle, para avaliação pedológica mais criteriosa, visando à confirmação das classes de solos previamente determinadas, assim como a corroboração da relação pedogeológica preliminar da área em estudo. $\mathrm{O}$ critério de seleção foi a representatividade desses perfis em relação às várias unidades geológicas, consideradas responsáveis pelo desenvolvimento das classes distintas de solos com horizontes B textural e B nítico. A representatividade destes perfis também levou em consideração a extensão territorial das unidades geológicas na área em questão. Foram, então, selecionados oito perfis de solos desenvolvidos a partir da unidade geológica DR, cinco nas unidades TTG e GBL, quatro nas unidades GI, GL e GBRM, três na unidade GCAP e um perfil representativo das unidades geológicas GG, GDT, GTT e GFM (Figura 2).

Na confirmação das classes de solo discriminadas na etapa anterior utilizou-se o critério de discriminação básica desses solos em relação ao teor de $\mathrm{Fe}_{2} \mathrm{O}_{3}$ do horizonte diagnóstico - $\mathrm{B}_{\mathrm{t}}$, de acordo com Embrapa (1999) e Oliveira et al. (1992), ou seja: PVA: $\mathrm{Fe}_{2} \mathrm{O}_{3}$ $<11$ dag kg-1; PV: 11 dag kg-1 $<\mathrm{Fe}_{2} \mathrm{O}_{3}<15$ dag kg-1; NVf e MTf: $\mathrm{Fe}_{2} \mathrm{O}_{3}>15$ dag kg-1. Os teores de $\mathrm{Fe}_{2} \mathrm{O}_{3}$ dos horizontes $\mathrm{B}_{\mathrm{t}}$ foram determinados no extrato do ataque sulfúrico, segundo método descrito por Vettori (1969) e Embrapa (1997).

Os perfis de solo de controle desenvolvidos a partir de unidades geológicas constituídas por rochas básicas e ultrabásicas foram classificados, na etapa anterior, como Nitossolos Vermelhos férricos com probabilidade de associação com Chernossolos Argilúvicos férricos. Para constatação da ocorrência destas classes de solos, os horizontes $\mathrm{A} \mathrm{e}_{\mathrm{t}}$ dos perfis correspondentes foram submetidos a análises granulométricas e análises químicas do complexo sortivo, visando ao cálculo da saturação de bases e da atividade da argila, além de análises de teores de matéria orgânica (C orgânico), uma vez que estes são atributos importantes na distinção destes solos e confirmação da ocorrência de Chernossolos. Para cálculo da atividade da argila, adotou-se a fórmula: $\mathrm{T}_{\text {argila }}=(\mathrm{T} \times 100) /\left(\right.$ argila $\left.\mathrm{dag} \mathrm{kg}^{-1}\right)$, conforme Embrapa (1999).

As análises granulométricas foram realizadas pelo método da pipeta, proposto por Day (1965) e as análises químicas para avaliação do complexo sortivo e teor de matéria orgânica foram realizadas segundo métodos descritos por Vettori (1969) e Embrapa (1997).

\section{Perfis de solos representativos}

Após avaliação dos perfis de controle, foram selecionados sete perfis representativos das classes de solos investigadas, dentre os 37 perfis estudados: PVA e PV, com dois perfis cada, e NVef, NVef chernossólico e MTf, com um perfil cada, para descrição morfológica completa, segundo critérios descritos em Lemos \& Santos (2005). Os perfis representativos foram utilizados para detalhamento da classificação no terceiro nível categórico do SiBCS (Embrapa, 1999) das classes de solo com horizontes B textural e B nítico que ocorrem na região, para aprimorar a relação pedogeológica. 


\section{Modelo de distribuição dos solos com horizontes $B$ textural e B nítico na paisagem}

A interpretação dos resultados foi auxiliada pela manipulação destes em um Sistema de Informação Geográfica (SIG), com o armazenamento dos dados obtidos em um banco de dados georreferenciados, implementado no Spring 4.0. Da área de estudo foram, também, implementados o mapa geológico com individualização geoquímica das unidades litológicas, obtido de Quéméneur (1995) e mapa de classes de declividade, extraído de Lacerda (1999).

Inicialmente, foi realizado um cruzamento entre o mapa geológico e mapa de classes de declividade, para individualização das unidades geológicas ígneas Arqueanas e Proterozóicas em áreas de desenvolvimento de solos com horizontes B textural e B nítico, ou seja, nas classes de declividade de 12 a $24 \mathrm{~cm} \mathrm{~m}^{-1}$. Esse produto foi denominado de distribuição pedomorfogeológica genérica da área de estudo, ainda sem individualização das classes de solos com horizontes B textural e B nítico.

Posteriormente, foi gerado um plano de informação temática com o atributo morfológico cor de Munsell avaliado nos 240 perfis de reconhecimento. Este foi cruzado com o plano de distribuição pedomorfogeológica genérica gerado, originando o plano temático denominado relação pedogeológica preliminar da área estudada, usando o critério de cor de Munsell para individualização das classes de solos com horizontes B textural e B nítico.

A partir dos 37 perfis selecionados e denominados de controle, foi gerado outro plano de informação com a inserção dos teores de $\mathrm{Fe}_{2} \mathrm{O}_{3}$, que permitiu a confirmação da relação pedogeológica preliminar por meio de outro cruzamento com o plano temático elaborado na etapa anterior.

Com os pontos de ocorrência de rochas de composição básica e ultrabásica, correspondentes às unidades geológicas GBRM, GBL e GFM, foram elaborados planos temáticos com dados de atividade de argila e saturação de bases do horizonte $B_{t} e$ presença de horizonte A chernozêmico. Esses dados foram, finalmente, cruzados entre si e com o plano temático da relação pedogeológica para associação dos atributos necessários à classificação de Chernossolo Argilúvico férrico. Após essas operações, o produto elaborado correspondeu à relação pedomorfogeológica da distribuição de solos com horizontes B textural e B nítico na paisagem de Lavras, em que todos os cruzamentos foram realizados por meio de programas em linguagem LEGAL, processados no Spring 4.0, elaborados a partir dos critérios e regras estabelecidos nas etapas anteriores para o modelo em pauta.

Finalmente, as unidades geológicas responsáveis pelo desenvolvimento de mesma classe de solos com horizontes B textural ou B nítico foram agrupadas para simplificação do modelo proposto, além de facilitar sua utilização. O critério de agrupamento foi o teor de $\mathrm{Fe}_{2} \mathrm{O}_{3}$ das unidades geológicas, pois foi a determinação geoquímica que representou melhor a relação pedogeológica estabelecida.

Essas relações consolidaram o modelo de distribuição de solos com horizonte B textural e B nítico na paisagem de Lavras (MG), que foi sumarizado por meio de uma tabela, com base na relação pedomorfogeoló-gica estabelecida para a área em estudo, constituída pela interação das relações pedogeomorfológicas e pedogeológicas, permitindo a individualização das unidades da paisagem, denominadas de geopedoformas. Estas representam a associação das unidades geológicas e geomorfológicas (classes de relevo, representadas por classes de declividade) responsáveis pelo desenvolvimento de classes distintas de solos com horizontes B textural e B nítico.

\section{RESULTADOS E DISCUSSÃO}

\section{Relação pedogeomorfológica}

O modelo pedogeomorfológico estabelecido para o município de Lavras por Andrade et al. (1998) (Quadro 4) foi utilizado nas campanhas de campo, para averiguação das classes de declividade (classes de relevo) de ocorrência dos solos com horizontes B textural e B nítico na área de estudo. Este modelo estabelece classe de declividade de 12 a $24 \mathrm{~cm} \mathrm{~m}^{-1}$ para desenvolvimento de solos com horizontes $\mathrm{B}$ textural e B nítico e de 24 a $45 \mathrm{~cm} \mathrm{~m}^{-1}$ para desenvolvimento destes em associação com Cambissolos. Essa relação pedogeomorfológica mostrou-se eficiente, possibilitando estendê-la para toda a área deste estudo, que engloba, além do município de Lavras, parte dos municípios de Nepomuceno, Carmo da Cachoeira, Itumirim, Nazareno e Itutinga, permitindo a utilização do mapa de classes de declividade da área de estudo obtido de Lacerda (1999).

No entanto, esta relação só contempla os grandes grupamentos de solos, com discriminação de classes de solos no primeiro e, às vezes, no segundo nível categórico do SiBCS (Embrapa, 1999). Para aprimorar a classificação dos solos com horizontes B textural e B nítico de ocorrência na área estudada, foi necessário o estabelecimento da relação pedogeológica.

O relevo predominante da região é do tipo "Mar de Morros”, associado às unidades geológicas ígneas Arqueanas, sendo constituído por colinas côncavoconvexas, onde se distribuem as classes de declividades de 0 a $12 \mathrm{~cm} \mathrm{~m}^{-1}$ e 12 a $24 \mathrm{~cm} \mathrm{~m}^{-1}$ em proporções aproximadamente equivalentes, com desenvolvimento de Latossolos e solos com horizontes B textural e B nítico. Já a classe de declive de 24 a $45 \mathrm{~cm} \mathrm{~m}^{-1}$ é menos freqüente, associada aos morros residuais, com desenvolvimento de Cambisssolos associados aos solos com horizontes B textural e B nítico. No município de Lavras, na porção sul predominam relevos planos a ondulados, enquanto na parte norte, em direção ao 
vale do Rio Grande, o relevo é mais dissecado, portanto, com porções de declividade mais acentuada, onde se destacam os solos com horizontes B textural e B nítico e Cambissolos. A classe de declividade de 0 a $3 \mathrm{~cm} \mathrm{~m}^{-1}$ é mais expressiva ao longo das planícies de inundação dos principais rios da região, como o Rio Grande e Rio Capivari e seus principais tributários.

De modo geral, a classe de declividade de 24 a $45 \mathrm{~cm} \mathrm{~m}^{-1}$ em associação com a classe $>45 \mathrm{~cm} \mathrm{~m}^{-1}$ ocorre de maneira esparsa, constituindo as porções mais montanhosas do relevo da região, geralmente relacionadas às unidades geológicas metassedimentares Proterozóicas, que se encontram soerguidas por mecanismos de falhamentos geológicos. Nestas áreas predominam Cambissolos, Neossolos Litólicos e Afloramentos Rochosos. Destaca-se a Serra de Bom Sucesso, com ocorrência de unidades metassedimentares do Supergrupo Minas, de ocorrência na porção centro-norte da área, entre os municípios de Rosário e Nazareno. A parte sul da área é limitada pela Serra da Bocaina, com ocorrência de litologias do Grupo Carrancas. Próximo ao município de Ijaci ocorre um maciço constituído por litologias do Supergrupo São João Del Rei.

\section{Relação pedogeológica}

No detalhamento da classificação dos solos estudados, segundo critérios do SiBCS (Embrapa, 1999), foi necessária a associação com estudos de relações pedogeológicas, auxiliando não só na classificação e avaliação da distribuição dos solos da área em pauta, como também fornecendo informações acerca dos atributos físicos e químicos dos solos.

\section{Relação pedogeológica - perfis de reconheci- mento}

Nos perfis de reconhecimento, dentre os atributos morfológicos avaliados, elegeu-se a cor e a atração magnética para discriminação prévia das classes de solo com horizontes B textural e B nítico e a elaboração preliminar da relação com as unidades geológicas ígneas Arqueanas e Proterozóicas que ocorrem na área de estudo, individualizadas pelas correspondentes composições geoquímicas (Quadros 1, 2 e 3 e Figura 2).
As rochas de composição básica e ultrabásica, como as rochas das unidades geológicas GBRM, GBL e GFM (Quadros 1, 2 e 3), apresentam alto teor de Fe com ocorrência de minerais silicatados ferromagnesianos e óxidos primários de Fe (Lacerda et al., 2000). Essas rochas apresentam desenvolvimento de solos com horizontes B textural e B nítico de cor bem avermelhada, com matiz $2,5 \mathrm{YR}$ ou mais vermelho, podendo atingir $10 \mathrm{R}$, com atração magnética forte, caracterizados como Nitossolos Vermelhos férricos possivelmente com associação de Chernossolo Argilúvico férrico, em função da caracterização morfológica de alguns horizontes A com atributos compatíveis à ocorrência de horizonte A chernozêmico, como espessura significativa e coloração muito escura.

Já as rochas de composição granítica e trondhjemítica-tonalítica são mais pobres em Fe (Quadros 2 e 3), como as litologias das unidades geológicas GI, TTG, GG e GTT e originam classes de solos com horizontes B textural de coloração vermelhoamarelada, com matiz predominante de $5 \mathrm{YR}$ ou mais vermelho e mais amarelo que $2,5 \mathrm{YR}$, sem atração magnética, indicativos dos baixos teores de Fe, caracterizados como Argissolos Vermelho-Amarelos.

As rochas de composição granodiorítica e charnockítica, como as unidades GL, GCAP e GDT, apresentam teor de Fe moderado na sua composição geoquímica (Quadros 2 e 3), e os solos correspondentes apresentam cores vermelhas a vermelho-amarelas com matiz variando de $2,5 \mathrm{YR}$ a $5 \mathrm{YR}$, classificados morfologicamente como Argissolos Vermelhos ou Argissolos Vermelho-Amarelos. Já a unidade Diorito do Rosário, de composição diorítica (sub-básica), apresenta teor de Fe mais elevado (Quadros 2 e 3) e, portanto, os solos desenvolvidos a partir desta litologia apresentam-se mais vermelhos que os anteriores e mostram atração magnética moderada a fraca atributos compatíveis com os Argissolos Vermelhos.

Assim, as relações entre os atributos morfológicos dos 240 perfis de reconhecimento, destacando-se cor e atração magnética, permitiram o estabelecimento da relação pedogeológica preliminar da área estudada, sumarizada no quadro 5.

Quadro 5. Relação pedogeológica preliminar da área estudada

Unidades geológicas
Classes de solos com horizontes B textural e B nítico
GBRM: Greenstone-Belt Rio das Mortes, GBL: Greenstone-Belt de Lavras e GFM: Gabro da Fazenda Martins

DR: Diorito do Rosário

GL: Gnaisses de Lavras, GCAP: Granulitos Calcio-Alcalino-Potássicos -

Charnockitos e GDT: Granodioritos Transamazônicos

GI: Granitos Transamazônicos de Itutinga, TTG: Gnaisses Tonalítico-

Trondhjemítico-Granodioríticos, GG: Gnaisses Graníticos e GTT:

Granulitos Trondhjemítico-Tonalíticos (Enderbitos)
Nitossolos Vermelhos férricos e Chernossolos Argilúvicos férricos Argissolos Vermelhos

Associação de Argissolos Vermelhos

e Argissolos Vermelho-Amarelos.

Argissolos Vermelho-Amarelos 


\section{Relação pedogeológica - perfis de controle}

Nos perfis de controle (Figura 2), a relação preliminar estabelecida foi checada com base no critério de discriminação dos solos estudados, por intermédio do teor de $\mathrm{Fe}_{2} \mathrm{O}_{3}$ do horizonte diagnóstico $\mathrm{B}_{\mathrm{t}}$ (Quadro 6).

Nas unidades geológicas TTG, GG, GTT e GI, os resultados analíticos de $\mathrm{Fe}_{2} \mathrm{O}_{3}$ dos solos correspondentes mostram valores menores que $11 \mathrm{dag} \mathrm{kg}^{-1}$, confirmando a classe Argissolo Vermelho-Amarelo, de acordo com o critério adotado. Nas unidades geológicas GL, GCAP e GDT, os teores de $\mathrm{Fe}_{2} \mathrm{O}_{3}$ comprovam o desenvolvimento de Argissolos Vermelho-Amarelos e Argissolos Vermelhos. No domínio geológico Diorito do Rosário (DR), o desenvolvimento de Argissolos Vermelhos, com valores de Fe entre 11 e 15 dag kg-1, também foi checado.

Já nos solos desenvolvidos a partir das unidades geológicas Gabro da Fazenda Martins (GFM), rochas de composição básica/ultrabásica do Greenstone-belt Rio das Mortes (GBRM) e Greenstone-belt de Lavras (GBL), também foram avaliadas a saturação de bases e atividade da argila e teores de matéria orgânica (C

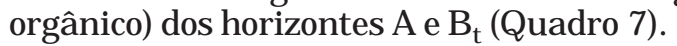

Os resultados da análise de $\mathrm{Fe}_{2} \mathrm{O}_{3}$ dos horizontes $\mathrm{B}_{\mathrm{t}}$ mostram valores $>15$ dag kg-1 $^{-1} \mathrm{e}$-juntamente com dados da atividade da argila e constatação da ocorrência de horizonte A chernozêmico - confirmam o desenvolvimento de Nitossolos Vermelhos férricos ou Chernossolos Argilúvicos férricos (Quadros 6 e 7).

Durante os trabalhos de caracterização dos solos desenvolvidos a partir dessas unidades geológicas foi constatada a ocorrência inédita de Chernossolo Argilúvico férrico na região de Lavras, no perfil 36, com atividade da argila de $37 \mathrm{cmol}_{\mathrm{c}} \mathrm{dm}^{-3}$ no horizonte $B_{t}$ (Quadro 7), além da ocorrência de horizonte A chernozêmico. Os resultados de atividade da argila em alguns solos estudados mostraram valores $>18 \mathrm{cmol}_{\mathrm{c}} \mathrm{dm}^{-3}$ (Quadro 7), indicando, juntamente com a presença de horizonte A chernozêmico de acordo com Oliveira et al. (1992), ocorrência de Nitossolos Vermelho eutroférrico transicional para Chernossolo Argilúvico férrico, ou Nitossolo Vermelho eutroférrico chernossólico (perfil 37), segundo Embrapa (1999).

Esses dados foram considerados os atributos morfológicos e químicos mais importantes na discriminação dos solos em estudo, dentre os demais estudados. Os dados completos das análises

Quadro 6. Unidade geológica associada, cor de Munsell, atração magnética e teor de $\mathrm{Fe}_{2} \mathrm{O}_{3}$ dos horizontes $\mathrm{Bt}$ dos perfis pedológicos de controle

\begin{tabular}{|c|c|c|c|c|c|c|c|c|c|}
\hline $\begin{array}{c}\text { Perfil } \\
\mathrm{N}^{\mathbf{0}}\end{array}$ & $\begin{array}{l}\text { Unidade } \\
\text { geológica }\end{array}$ & $\begin{array}{c}\text { Cor de } \\
\text { Munsell }\end{array}$ & $\begin{array}{l}\text { Atração } \\
\text { magnet. }\end{array}$ & $\mathrm{Fe}_{2} \mathrm{O}_{3}$ & $\begin{array}{c}\text { Perfil } \\
\mathrm{N}^{\mathbf{0}}\end{array}$ & $\begin{array}{l}\text { Unidade } \\
\text { geológica }\end{array}$ & Cor Munsell & $\mathrm{Fe}_{2} \mathrm{O}_{3}$ & $\begin{array}{l}\text { Atração } \\
\text { magnet. }\end{array}$ \\
\hline
\end{tabular}

\begin{tabular}{|c|c|c|c|c|c|c|c|c|}
\hline \multirow[b]{2}{*}{ GI } & \multicolumn{5}{|c|}{ dag $\mathrm{kg}^{-1}$} & \multicolumn{3}{|c|}{ dag $\mathrm{kg}^{-1}$} \\
\hline & $5 Y R 5 / 8$ & ausente & 2,0 & 20 & $\mathrm{DR}$ & $2,5 \mathrm{YR} 4 / 8$ & 11,00 & moderada \\
\hline GI & $5 \mathrm{YR} / 7 / 7$ & ausente & 1,5 & 21 & $\mathrm{DR}$ & $2,5 \mathrm{YR} 4 / 3$ & 11,1 & moderada \\
\hline GI & 7,5YR 6/4 & ausente & 1,6 & 22 & DR & $2,5 \mathrm{YR} 4 / 6$ & 11,7 & moderada \\
\hline GI & $5 \mathrm{YR} 5 / 8$ & ausente & 2,0 & 23 & DR & $2,5 \mathrm{YR} 4 / 6$ & 11,4 & moderada \\
\hline TTG & $5 \mathrm{YR} 5 / 8$ & ausente & 8,9 & 24 & DR & 5YR 4/6 & 13,1 & moderada \\
\hline $\mathrm{TTG}$ & $5 \mathrm{YR} 5 / 8$ & ausente & 8,8 & 25 & $\mathrm{DR}$ & $2,5 \mathrm{YR} 3 / 6$ & 14,3 & moderada \\
\hline $\mathrm{TTG}$ & $5 \mathrm{YR} 5 / 6$ & ausente & 8,8 & 26 & $\mathrm{DR}$ & $2,5 \mathrm{YR} 4 / 6$ & 13,9 & moderada \\
\hline $\mathrm{TTG}$ & $5 \mathrm{YR} 6 / 4$ & ausente & 5,6 & 27 & $\mathrm{DR}$ & $2,5 \mathrm{YR} 3 / 6$ & 10,8 & moderada \\
\hline TTG & $2,5 \mathrm{YR} 3 / 4$ & ausente & 9,8 & 28 & GFM & $2,5 \mathrm{YR} 3 / 6$ & 21,0 & forte \\
\hline GTT & $5 \mathrm{YR} 5 / 6$ & ausente & 5,2 & 29 & GBRM & $5 \mathrm{YR} 5 / 8$ & 21,6 & forte \\
\hline GG & $5 \mathrm{YR} 7 / 8$ & ausente & 4,7 & 30 & GBRM & 10YR 4/6 & 24,5 & forte \\
\hline GL & $5 \mathrm{YR} 5 / 3$ & fraca & 5,0 & 31 & GBRM & $10 \mathrm{R} 4 / 6$ & 22,0 & forte \\
\hline GDT & $2,5 \mathrm{YR} 4 / 4$ & fraca & 13,7 & 32 & GBRM & 2,5YR6/5 & 21,0 & forte \\
\hline GL & $2,5 \mathrm{YR} 5 / 4$ & fraca & 9,4 & 33 & GBL & $2,5 \mathrm{YR} 5 / 8$ & 16,1 & forte \\
\hline GL & $5 \mathrm{YR} 3 / 2$ & fraca & 4,7 & 34 & GBL & $2,5 \mathrm{YR} 5 / 8$ & 19,6 & forte \\
\hline $\mathrm{GL}$ & $2,5 \mathrm{YR} 4 / 6$ & fraca & 8,7 & 35 & GBL & $2,5 \mathrm{YR} / 3 / 6$ & 16,4 & forte \\
\hline GCAP & $5 \mathrm{YR} 5 / 4$ & fraca & 3,5 & 36 & GBL & $2,5 \mathrm{YR} 3 / 6$ & 21,3 & forte \\
\hline GCAP & $2,5 \mathrm{YR} 4 / 4$ & fraca & 11,4 & 37 & GBL & 2,5YR5/8 & 19,7 & forte \\
\hline GCAP & $2,5 \mathrm{YR} 5 / 8$ & fraca & 11,7 & - & - & - & - & - \\
\hline
\end{tabular}

TTG: Gnaisse Pau da Bandeira; GL: Gnaisses Granodioríticos de Lavras; GG: Gnaisses Graníticos; GCAP: Granulitos CálcioAlcalino-Potássicos - Charnockitos; GTT: Granulitos Tonalítico-Trondhjemíticos - Enderbitos; GBRM: Anfibolitos e Rochas Ultrabásicas do Greenstone-belt Rio das Mortes; GBL: Anfibolitos e Rochas Ultrabásicas do Greenstone-belt de Lavras; DR: Diorito do Rosário; GFM: Gabro da Fazenda Martins; GI: Granito de Itutinga; GDT: Granodioritos Transamazônicos. 
Quadro 7. Atributos físicos e químicos dos solos e desenvolvimento a partir das unidades geológicas Gabro da Fazenda Martins (GFM), Greenstone-belt Rio das Mortes (GBRM) e Greenstone-belt de Lavras (GBL)

\begin{tabular}{|c|c|c|c|c|c|c|c|c|}
\hline Perfil $N^{o}$ & Horiz. & Teor de argila & Classificação textural ${ }^{(1)}$ & $\mathbf{V}$ & $\mathbf{T}_{\text {solo }}$ & $\mathbf{T}_{\text {argila }}$ & $\mathrm{MO}^{(2)}$ & C orgânico \\
\hline & & dag $\mathrm{kg}^{-1}$ & & $\%$ & \multicolumn{2}{|c|}{$-\mathrm{cmol}_{\mathrm{c}} \mathrm{dm}^{-3}-$} & \multicolumn{2}{|c|}{$\mathrm{g} \mathrm{kg}^{-1}$} \\
\hline \multirow[t]{2}{*}{28} & $\mathrm{~A}$ & 62 & Muito Argilosa & 74,5 & 11,4 & 18,4 & 25 & 14 \\
\hline & $\mathrm{Bt}$ & 68 & Muito Argilosa & 73,1 & 7,8 & 11,5 & 14 & 8 \\
\hline \multirow[t]{2}{*}{29} & $\mathrm{~A}$ & 50 & Argilosa & 78,5 & 7,9 & 15,8 & 28 & 16 \\
\hline & $\mathrm{Bt}$ & 67 & Muito Argilosa & 57,9 & 5,5 & 8,2 & 12 & 7 \\
\hline \multirow[t]{2}{*}{30} & $\mathrm{~A}$ & 43 & Argilosa & 26,7 & 4,0 & 9,3 & 31 & 18 \\
\hline & $\mathrm{Bt}$ & 57 & Argilosa & 41,3 & 3,2 & 5,6 & 13 & 7 \\
\hline \multirow[t]{2}{*}{31} & $\mathrm{~A}$ & 36 & Argilosa & 17,7 & 4,4 & 12,2 & 32 & 18 \\
\hline & $\mathrm{Bt}$ & 53 & Argilosa & 21,7 & 4,1 & 7,7 & 15 & 9 \\
\hline \multirow[t]{2}{*}{32} & A & 54 & Argilosa & 5,7 & 3,6 & 6,7 & 24 & 14 \\
\hline & $\mathrm{Bt}$ & 63 & Muito Argilosa & 6,6 & 3,6 & 5,7 & 11 & 6 \\
\hline \multirow[t]{2}{*}{33} & $\mathrm{~A}$ & 39 & Argilosa & 61,3 & 6,4 & 16,4 & 27 & 16 \\
\hline & $\mathrm{Bt}$ & 50 & Argilosa & 40,2 & 6,0 & 12,0 & 10 & 6 \\
\hline \multirow[t]{2}{*}{34} & $\mathrm{~A}$ & 31 & Média & 40,0 & 7,3 & 23,5 & 30 & 17 \\
\hline & $\mathrm{Bt}$ & 40 & Argilosa & 52,9 & 7,5 & 18,8 & 16 & 9 \\
\hline \multirow[t]{2}{*}{35} & $\mathrm{~A}$ & 48 & Argilosa & 64,8 & 9,1 & 19,0 & 32 & 18 \\
\hline & $\mathrm{Bt}$ & 57 & Argilosa & 70,3 & 7,7 & 13,5 & 17 & 10 \\
\hline \multirow[t]{2}{*}{36} & A & 36 & Argilosa & 79,0 & 17,0 & 47,2 & 36 & 21 \\
\hline & $\mathrm{Bt}$ & 52 & Argilosa & 87,0 & 19,4 & 37,0 & 11 & 6 \\
\hline \multirow[t]{2}{*}{37} & A & 35 & Argilosa & 53,6 & 7,8 & 22,3 & 31 & 18 \\
\hline & $\mathrm{Bt}$ & 45 & Argilosa & 64,7 & 9,1 & 20,2 & 16 & 9 \\
\hline
\end{tabular}

${ }^{(1)}$ Embrapa (1997). ${ }^{(2)}$ Matéria orgânica. V: saturação por bases, T: CTC a pH 7.

granulométricas e do complexo sortivo realizadas nesses perfis estão disponíveis nos trabalhos de Lacerda (1999) e Rebellatto (2000).

Ressalta-se que alguns dos trabalhos anteriores realizados nessa região, como os de Andrade (1979) e Rocha (1982), envolvendo relações entre classes de solos e material de origem genérico, associam o desenvolvimento de Nitossolos Vermelhos férricos, assim como o dos Latossolos Vermelhos férricos, com diques de gabro. O mapeamento geológico inédito utilizado neste estudo não apresenta diques de gabro, por questão de escala de mapeamento, uma vez que estes apresentam pequenas espessuras, apesar da ocorrência comum. Nenhum outro mapeamento geológico apresenta as unidades geológicas básicas e ultrabásicas discutidas neste trabalho, com expressiva distribuição areal. Assim, durante a realização deste trabalho foi possível constatar a associação dos Nitossolos Vermelhos férricos, bem como Chernossolos
Argilúvicos férricos, com as unidades geológicas Gabro da Fazenda Martins (GFM), rochas de composição básica/ultrabásica do Greenstone-Belt Rio das Mortes (GBRM) e Greenstone-Belt de Lavras (GBL); os diques de gabro podem colaborar quando associados, mas não são os responsáveis pela gênese dos solos em discussão.

\section{Relação pedogeológica - perfis representativos}

Os perfis representativos das classes de solo com horizontes B textural e B nítico de ocorrência na região foram avaliados, a fim de corroborar os atributos pedogenéticos relacionados ao material de origem, para uma classificação mais acurada, segundo normas do SiBCS (Embrapa, 1999). Os dados morfológicos, físicos e químicos desses encontram-se descritos em Lacerda (1999) e Rebellatto (2000).

Os perfis selecionados e sua classificação de acordo com o SiBCS (Embrapa, 1999) podem ser observados no quadro 8. 
Quadro 8. Classificação dos solos dos perfis representativos estudados, de acordo com o SiBCS

\begin{tabular}{|c|c|}
\hline Perfil & Classificação dos solos (SiBCS) \\
\hline Perfil 1 e 2 & $\begin{array}{l}\text { Argissolo Vermelho-Amarelo distrófico argila de atividade baixa A moderado textura média fase } \\
\text { campo tropical relevo forte ondulado substrato rochas graníticas- Granito de Itutinga - GI }\end{array}$ \\
\hline Perfil 20 e 21 & $\begin{array}{l}\text { Argissolo Vermelho eutrófico argila de atividade baixa A moderado textura média/argilosa fase } \\
\text { floresta tropical subcaducifólia relevo forte ondulado substrato rochas dioríticas - Diorito do } \\
\text { Rosário - DR }\end{array}$ \\
\hline Perfil 34 & $\begin{array}{l}\text { Nitossolo Vermelho eutroférrico argila de atividade baixa A moderado textura argilosa fase } \\
\text { floresta tropical subcaducifólia relevo forte ondulado substrato rochas básicas/ultrabásicas - } \\
\text { Greenstone-Belt de Lavras - GBL }\end{array}$ \\
\hline Perfil 36 & $\begin{array}{l}\text { Chernossolo Argilúvico férrico textura argilosa fase floresta tropical subcaducifólia relevo forte } \\
\text { ondulado substrato rochas básicas/ultrabásicas - Greenstone-Belt de Lavras - GBL }\end{array}$ \\
\hline Perfil 37 & $\begin{array}{l}\text { Nitossolo Vermelho eutroférrico chernossólico argila de atividade }>18 \mathrm{cmol}_{\mathrm{c}} \mathrm{dm}^{-3} \mathrm{~A} \text { chernozêmico } \\
\text { textura argilosa fase floresta tropical subcaducifólia relevo forte ondulado substrato rochas } \\
\text { básicas/ultrabásicas - Greenstone-Belt de Lavras - GBL. }\end{array}$ \\
\hline
\end{tabular}

Fonte: Embrapa (1999).

\section{Modelo de distribuição de solos com horizon- tes $B$ textural e $B$ nítico na paisagem}

A relação pedogeomorfológica da área de estudo foi checada em atividades de campo, utilizando o mapa de classes de declividade obtido de Lacerda (1999), elaborado conforme modelo proposto para o município de Lavras por Andrade et al. (1998).

As avaliações realizadas nos perfis de reconhecimento, de controle e representativos permitiram o estabelecimento da relação pedogeológica associada à relação pedogeomorfológica da área investigada, que foi, neste trabalho, denominada de relação pedomorfogeológica. A interpretação dos dados obtidos nas várias etapas do trabalho com os dados geológicos e geoquímicos extraídos de Quéméneur (1995) e dados de relevo (classes declividade) obtidos de Lacerda (1999) em ambiente SIG auxiliaram a elaboração do modelo de distribuição dos solos com horizontes B textural e B nítico na paisagem de Lavras.

Como a composição do solo é dependente da constituição geoquímica do material de origem e o teor de $\mathrm{Fe}_{2} \mathrm{O}_{3}$ em uma rocha encontra-se vinculado à sua composição geoquímica global, assim como sua classificação petrológica e composição mineralógica essencial, as unidades geológicas foram, então, agrupadas em função dos seus teores de $\mathrm{Fe}_{2} \mathrm{O}_{3}$, para facilitar a utilização e interpretação do modelo, da seguinte maneira: (a) rochas com conteúdo muito baixo de $\mathrm{Fe}_{2} \mathrm{O}_{3}(\leq 2,0$ dag kg-1) - unidade geológica GI; (b) rochas com conteúdo baixo de $\mathrm{Fe}_{2} \mathrm{O}_{3}(>2$ a 3 dag kg-1) - unidades geológicas TTG, GTT e GG; (c) rochas com conteúdo médio de $\mathrm{Fe}_{2} \mathrm{O}_{3}\left(3\right.$ a 5 dag $\left.\mathrm{kg}^{-1}\right)$ - unidades geológicas GL, GDT e GCAP; (d) rochas com conteúdo alto de $\mathrm{Fe}_{2} \mathrm{O}_{3}$ (5 a 8 dag $\left.\mathrm{kg}^{-1}\right)$ - unidade geológica $\mathrm{DR}$; e (e) rochas com conteúdo muito alto de $\mathrm{Fe}_{2} \mathrm{O}_{3}$ (> 8 dag $\mathrm{kg}^{-1}$ ) - unidades geológicas GFM, GBRM e GBL.

Além de o teor $\mathrm{Fe}_{2} \mathrm{O}_{3}$ representar o melhor atributo geoquímico de agrupamento das unidades geológicas, este foi, também, embasado nos estudos de alteração e pedogênese realizados por Cerri (1979) e Clemente (1988) em rochas graníticas; Oliveira (1980), Gonçalves (1987) e Menegotto \& Gasparetto (1987), em rochas básicas e ultrabásicas; e Lacerda et al. (2002a,b), nos estudos de evolução pedogeoquímica nos perfis representativos de solos com horizontes B textural e B nítico na região de Lavras, desenvolvidos sobre rochas de composição geoquímica variada.

Com as classes de rochas agrupadas em relação ao teor de $\mathrm{Fe}_{2} \mathrm{O}_{3}$, as unidades da paisagem foram individualizadas por meio da associação das unidades geológicas e geomorfológicas (classes de relevo), representadas por classes de declividade, estabelecendo-se as relações pedomorfogeológicas na área estudada, apresentadas no quadro 9. Essa relação representa a proposição do modelo preditivo de distribuição de solos na paisagem da região de Lavras (MG), cujas unidades da paisagem foram denominadas de geopedoformas, responsáveis pelo desenvolvimento de classes distintas de solos com horizontes B textural e B nítico. 
Quadro 9. Modelo de distribuição de solos com horizontes B textural e B nítico da região de Lavras (MG)

\begin{tabular}{|c|c|c|c|c|}
\hline \multicolumn{4}{|c|}{ Geopedoformas - Relação pedomorfogeológica } & \multirow{2}{*}{$\begin{array}{c}\text { Classes de solos com horizontes B } \\
\text { textural e B nitico }\end{array}$} \\
\hline $\begin{array}{l}\text { Unidades geológicas } \\
\text { agrupadas }\end{array}$ & $\begin{array}{l}\text { Teor de } \\
\mathrm{Fe}_{2} \mathrm{O}_{3}\end{array}$ & $\begin{array}{l}\text { Classes de } \\
\text { relevo }\end{array}$ & $\begin{array}{c}\text { Classes de } \\
\text { declividade }\end{array}$ & \\
\hline & dag $\mathrm{kg}^{-1}$ & & $\mathrm{~cm} \mathrm{~m}^{-1}$ & \\
\hline GI: Granito de Itutinga & $<2$ & $\begin{array}{l}\text { Ondulado a } \\
\text { forte ondulado }\end{array}$ & $12-45$ & $\begin{array}{l}\text { Argissolo Vermelho-Amarelo distrófico } \\
\text { argila de atividade baixa A moderado } \\
\text { textura média. }\end{array}$ \\
\hline $\begin{array}{l}\text { TTG: Gnaisse Pau da } \\
\text { Bandeira, GTT: Granulitos } \\
\text { Tonalítico-Trondhjemíticos- } \\
\text { Enderbitos e GG: Gnaisses } \\
\text { Graníticos }\end{array}$ & $2-3$ & $\begin{array}{l}\text { Ondulado a } \\
\text { forte ondulado }\end{array}$ & $12-45$ & $\begin{array}{l}\text { Argissolo Vermelho-Amarelo } \\
\text { distrófico/eutrófico argila de atividade } \\
\text { baixa A moderado textura média. }\end{array}$ \\
\hline $\begin{array}{l}\text { GL - Gnaisses Granodioríticos } \\
\text { de Lavras, GDT: Granodioritos } \\
\text { Transamazônicos e GCAP: } \\
\text { Granulitos Cálcio-Alcalino- } \\
\text { Potássicos (Charnockitos) }\end{array}$ & $3-5$ & $\begin{array}{l}\text { Ondulado a } \\
\text { forte ondulado }\end{array}$ & $12-45$ & $\begin{array}{l}\text { Associação Argissolo Vermelho- } \\
\text { Amarelo distrófico/eutrófico argila de } \\
\text { atividade baixa A moderado textura } \\
\text { média/argilosa + Argissolo Vermelho } \\
\text { distrófico/eutrófico argila de atividade } \\
\text { baixa A moderado textura } \\
\text { média/argilosa. }\end{array}$ \\
\hline DR: Diorito do Rosário & $5-8$ & $\begin{array}{l}\text { Ondulado a } \\
\text { forte ondulado }\end{array}$ & $12-45$ & $\begin{array}{l}\text { Argissolo Vermelho eutrófico argila de } \\
\text { atividade baixa A moderado textura } \\
\text { média/argilosa. }\end{array}$ \\
\hline $\begin{array}{l}\text { GFM: Gabro da Fazenda } \\
\text { Martins, GBRM: Anfibolitos e } \\
\text { Rochas Ultrabásicas do } \\
\text { Greenstone-belt Rio das } \\
\text { Mortes e GBL: Anfibolitos e } \\
\text { Rochas Ultrabásicas do } \\
\text { Greenstone-belt de Lavras }\end{array}$ & $>8$ & $\begin{array}{l}\text { Ondulado a } \\
\text { forte ondulado }\end{array}$ & $12-45$ & $\begin{array}{l}\text { Associação Nitossolo Vermelho } \\
\text { eutroférrico/distroférrico argila de } \\
\text { atividade baixa A moderado textura } \\
\text { argilosa a média/argilosa }+ \text { Nitossolo } \\
\text { Vermelho eutroférrico chernossólico } \\
\text { argila de atividade }>18 \mathrm{cmol}_{\mathrm{c}} \mathrm{dm}^{-3} \mathrm{~A} \\
\text { chernozêmico textura argilosa a } \\
\text { média/argilosa + Chernossolo } \\
\text { Argilúvico férrico textura } \\
\text { média/argilosa. }\end{array}$ \\
\hline
\end{tabular}

\section{CONCLUSÕES}

1. O modelo proposto de distribuição dos solos com horizontes B textural e B nítico na paisagem de Lavras (MG) foi embasado no estabelecimento de relações pedomorfogeológicas, em que os materiais de origem foram agrupados em relação ao teor de $\mathrm{Fe}_{2} \mathrm{O}_{3}$ das unidades geológicas correspondentes, cuja composição geoquímica diferenciada é responsável pelo desenvolvimento de classes distintas de solos com horizontes B textural e B nítico (PV, PVA, NVf, NVf chernossólico e MTf) em classes de declividade de 12 a $45 \mathrm{~cm} \mathrm{~m}^{-1}$.

2. O estudo realizado oferece subsídios para identificação dos solos com horizontes B textural e B nítico de ocorrência na região estudada, por meio da verificação da classe de declividade entre $12 \mathrm{e} 45 \mathrm{~cm} \mathrm{~m}^{-1}$ e de alguns atributos pedológicos associados ao material de origem. Dentre os atributos avaliados, destacamse os atributos morfológicos cor e atração magnética $\mathrm{e}$ teor de $\mathrm{Fe}_{2} \mathrm{O}_{3}$. A atividade da argila dos horizontes $\mathrm{B}_{\mathrm{t}}$ e o teor da matéria orgânica e saturação por bases dos horizontes A representam os atributos adicionais para individualização de Nitossolos Vermelhos férricos e Chernossolos Argilúvicos férricos, desenvolvidos a partir de unidades geológicas de composição básica/ ultrabásica, agrupadas pelo teor de $\mathrm{Fe}_{2} \mathrm{O}_{3}>8$ dag kg-1 .

3. Como a região não apresenta mapeamentos pedológicos, geomorfológicos e geológicos de detalhe, 0 modelo proposto pode ser utilizado na elaboração de mapeamentos pedológicos com individualização de solos com horizontes B textural e B nítico da região de estudo, a fim de auxiliar estudos pedológicos de diversas naturezas.

\section{LITERATURA CITADA}

ANDRADE, H. Caracterização genética, morfológica e classificação de dois solos do município de Lavras - MG em correlação com a geomorfologia da área. Lavras, Escola Superior de Agricultura de Lavras, 1979. 79p. (Tese de Mestrado) 
ANDRADE, H.; ALVES, H.M.R.; VIEIRA, T.G.C.; RESENDE, R.J.T.P.; ESTEVES, D.R.; BRASIL, J.K. \& ROSA, E.R. Diagnóstico ambiental do município de Lavras com base em dados georreferenciados do meio físico: IV - Principais grupamentos de solos. In: CONGRESSO BRASILEIRO DE ENGENHARIA AGRÍCOLA, 27., Poços de Caldas, 1998. Anais. Poços de Caldas, Universidade Federal de Lavras /Sociedade Brasileira de Engenharia Agrícola, 1998. v.4. p.442-443

BOULET, R. Toposéquences de sols tropicaux en Haute Volta - Équilibre et déséquilibre pédobioclimatique. Paris, ORSTOM, 1978. 272p. (Mémories, 85)

BUOL, S.W.; HOLE, F.D. \& McCRAKEN, R.J. Soil genesis and classification. 3.ed. Ames, Iowa University Press, 1989. $446 \mathrm{p}$.

CERRI, C.C. Alteração e pedogênese em áreas graníticas situadas sob diferentes condições bioclimáticas encontradas no Brasil. São Paulo, Universidade de São Paulo, 1979. 241p. (Tese de Doutorado)

CLEMENTE, C.A. Alterações e solos desenvolvidos sobre rochas vulcânicas ácidas da Formação Serra Geral nos Planaltos de Guarapuava e Palmas, Região Centro Sul do Estado do Paraná. Piracicaba, Escola Superior de Agricultura Luiz de Queiroz, 1988. 211p. (Tese de Doutorado)

CURI, N.; LIMA, J.M.; ANDRADE, H. \& GUALBERTO, V. Geomorfologia, física, química e mineralogia dos principais solos da região de Lavras (MG). Ci. Prática, 14:297-307, 1990 .

DAY, P.R. Particle fractionation and particle size analysis. In: BLACK, C.A., ed. Methods of soil analysis physical and mineralogical properties, including statistics of measurement and sampling. Madison, American Society of Agronomy, 1965. p.545-566.

DELVIGNE, J. Pédogenèse en zone tropicale - La formation des minéraux secondaires em milieu ferrallitique. Paris, ORSTOM, 1965. 177p.

EMPRESA BRASILEIRA DE PESQUISA AGROPECUÁRIA EMBRAPA. Centro Nacional de Pesquisas de Solos. Sistema brasileiro de classificação de solos. Brasília, Embrapa Produção de Informação, 1999. 412p.

EMPRESA BRASILEIRA DE PESQUISA AGROPECUÁRIA EMBRAPA. Centro Nacional de Pesquisas de Solos. Manual de métodos de análise de solos. 2.ed. Rio de Janeiro, Embrapa-CNPS, 1997. 212p. (Documentos, 1)

EMPRESA BRASILEIRA DE PESQUISA AGROPECUÁRIA EMBRAPA. Serviço Nacional de Levantamento e Conservação de Solos. Normas e critérios para levantamentos pedológicos. Rio de Janeiro, EmbrapaSNLCS, 1989. 94p.

GASPARETTO, N.V.L. \& MENEGOTTO, E. Comportamento dos elementos Terras Raras na intemperização de rochas vulcânicas ácidas em clima subtropical. In: CONGRESSO BRASILEIRO DE GEOQUÍMICA, 5.; CONGRESSO DE GEOQUÍMICA DOS PAÍSES DE LÍNGUA PORTUGUESA, 3., Niterói, 1995. Resumos. Niterói, Sociedade Brasileira de Geoquímica, 1995.
GIAROLA, N.F.B. Levantamento pedológico, perdas de solo e aptidão agrícola das terras da região sob influência do reservatório de Itutinga/Camargos (MG). Lavras, Universidade Federal de Lavras, 1994. 226p. (Tese de Mestrado)

GONÇALVES, N.M.M. Transformações mineralógicas e estruturais relacionadas à alteração hidrotermal e intempérica de rochas vulcânicas básicas da Bacia do Paraná Setentrional - Região de Ribeirão Preto -SP, Brasil. São Paulo, Universidade de São Paulo, 1987. 212p. (Tese de Doutorado)

LACERDA, M.P.C. Correlação geo-pedológica na região de Lavras (MG). Lavras, Universidade Federal de Lavras, 1999. 257p. (Tese de Doutorado)

LACERDA, M.P.C.; ANDRADE, H. \& QUEMÉNEUR, J.J.G. Micropedologia da alteração em perfis de solos com B textural na região de Lavras, Minas Gerais. R. Bras. Ci. Solo, 24:829-841, 2000.

LACERDA, M.P.C.; ANDRADE, H. \& QUEMÉNEUR, J.J.G. Pedogeoquímica em perfis de alteração na Região de Lavras (MG). I - Elementos maiores - Óxidos constituintes. R. Bras. Ci. Solo, 26:75-86, 2002a.

LACERDA, M.P.C.; ANDRADE, H. \& QUEMÉNEUR, J.J.G. Pedogeoquímica em perfis de alteração na Região de Lavras (MG). II - Elementos menores e elementos das terras raras. R. Bras. Ci. Solo, 26:87-102, 2002b.

LEMOS, R.C. \& SANTOS, R.D. Manual de descrição e coleta de solo no campo. 3.ed. Campinas, SBCS/SNLCS, 2005. 45p.

MARQUES Jr., J. Litocronossequência de solos da Região de Lavras (MG). Lavras, Universidade Federal de Lavras, 1988. 78p. (Tese de Mestrado)

MARQUES Jr., J.; CURI, N. \& LIMA, J.M. Evolução diferenciada de Latossolo Vermelho-Amarelo e Latossolo Vermelho-Escuro em função da litologia gnáissica na região de Lavras (MG). R. Bras. Ci. Solo, 16:235-240, 1992.

MENEGOTTO, E. \& GASPARETTO, N.V.L. Intemperização de rochas vulcânicas básicas e ácidas na região de Santa Maria - RS. In: CONGRESSO BRASILEIRO DE GEOQUÍMICA, 1., Santa Maria, 1987. Anais. Santa Maria, Sociedade Brasileira de Geoquímica, 1987. v.2. p.69-83.

OLIVEIRA, J.B. Pedologia aplicada. 2.ed. Piracicaba, FEALQ, 2005. 574p.

OLIVEIRA, J.B.; JACOMINE, P.K.T. \& CAMARGO, M.N. Classes gerais de solos do Brasil: Guia auxiliar para seu reconhecimento. Jaboticabal, FUNEP, 1992. 201p.

OLIVEIRA, S.M.B. Alteração intempérica das rochas ultrabásicas de Santa Fé (GO) e gênese do depósito niquelífero. São Paulo, Universidade de São Paulo, 1980. 216p. (Tese de Doutorado)

QUÉMÉNEUR, J.J.G. Os magmatismos de idade arqueana e transamazônica na região Campos das Vertentes. MG (Sul do Cráton do São Francisco), com base em geoquímica e geocronologia. Belo Horizonte, CPMTC-IGC-UFMG, 1995. $79 \mathrm{p}$

REBELLATTO, A. Distribuição de solos B texturais da região de Lavras-MG, referenciada por correlação geopedológica. Lavras, Universidade Federal de Lavras, 2000. 79p. (Tese de Mestrado) 
RESENDE, M.; CURI, N.; REZENDE, S.B. \& CORRÊA, G.F. Pedologia: Base para distinção de ambientes. Viçosa, MG, NEPUT, 2005. 304p.

ROCHA, G.C. Geologia, geomorfologia e pedologia de uma catena de solos situada no campus da Escola Superior de Agricultura de Lavras (MG). Lavras, Escola Superior de Agricultura de Lavras, 1982. 109p. (Tese de Mestrado)
SILVA, A.C.; LIMA, J.M. \& CURI, N. Relações entre voçorocas, usos da terra, solos e materiais de origem na região de Lavras (MG). R. Bras. Ci. Solo, 17:459-464, 1993.

VETTORI, L. Métodos de análise de solo. Rio de Janeiro, Equipe de Pedologia e Fertilidade de solo, Embrapa/SNLS, 1969. 34p. (Boletim Técnico, 7) 